\title{
EREBEA
}

Revista de Humanidades

y Ciencias Sociales

Núm. 3 (2013), pp. 71-102

ISSN: 0214-0691

\section{El caballero en el mar: don Pero Niño, conde de Buelna, entre el Mediterráneo y el Atlántico}

\author{
Rafael Beltrán \\ Universitat de València
}

RESUMEN

El artículo se propone repasar y actualizar datos en torno a la vida de uno de los más significados caballeros del otońo de la Edad Media castellana, cotejando estos datos con el avance en los estudios sobre su principal testimonio biográfico, que es a su vez uno de los textos literarios medievales clásicos. Nacido hacia 1378, Pero Niño, futuro conde de Buelna, se educó en el ambiente de la corte real, donde su madre sirvió como ama de cría del futuro rey Enrique III. Hacia 1430, Gutierre Díaz de Games empezaría a escribir sus hechos en forma de extensa biografía. El Victorial es un documento crucial para la historia de Espańa y Francia, especialmente significativo para la historia militar y de la marina, porque las aventuras de Pero Niño le condujeron, entre 1404 y 1406 , desde la costa de la Berbería hasta las costas de Inglaterra y desde la corte de Castilla a la de Francia. De regreso en Castilla, participaría en la campaña contra Granada dirigida por Fernando de Antequera, futuro rey de Aragón.

Palabras Clave

Pero Niño, conde de Buelna, biografía medieval, El Victorial.

Fecha de recepción: 13 de julio de 2013

Fecha de aceptación: 31 de julio de 2013
ABSTRACT

The article aims to update data about the life of one of the most relevant Medieval Castilian knights, Pero Niño. It compares these data with the information retrieved in scholarly works about his biographical narrative, one of the most important classic Spanish medieval texts. Born around 1378, Pero Niño, future count of Buelna, was raised in the royal household where his mother served as nursemaid to the future King Enrique III. Around the early 1430s, Gutierre Díaz de Games began to write the account of Niño's deeds. The Victorial is a crucial document of the history of Spain and France, especially significant for both medieval military and marine history, because the adventures of Pero Niño took him, between 1404 and 1406, from the Berber Coast to the shores of England, and from the court of Castile to that of France. Back in Castile, he participated in the latest campaign against Moorish Granada, directed by Fernando de Antequera, later King Fernando of Aragon.

\section{KEYWORDS}

Pero Nińo, count of Buelna, medieval biography, El Victorial. 



\section{i. La vida de Pero Niño y el testimonio biográfico de El Victorial}

Seguramente muchos caballeros, de entre los que corrieron entre los valles y navegaron entre los mares de los reinos hispánicos durante el siglo XV, gozaron de una vida tan intensa, o incluso más intensa que la de Pero Niño, capitán de las galeras castellanas en el Mediterráneo y en el Atlántico durante el reinado de Enrique III de Castilla, que alcanzaría el condado de Buelna durante el de Juan II. Sin embargo, aunque lo merecieran tantos, muy pocos -o casi ninguno- contaron con la fortuna de que sus acciones fueran escritas de manera tan detallada, inspirada y entusiasta como le iba a ocurrir a don Pero Niño.

El Victorial es el título de la extensa biografía que le escribió, por encargo y por devoción de hombre criado en su casa, Gutierre Díaz de Games. Gracias a ese extenso escrito - más de trescientas densas páginas, en el formato medio de una edición moderna-, contamos con el legado de un relato cumplido y pormenorizado de largos retazos de la agitada y aventurera vida de Pero Niño. El Victorial pasó, como libro, desconocido para los grandes autores literarios, como sucedería con la mayoría de las obras medievales que quedaron en latencia a lo largo de los siglos XVI y XVII. La historia del conde de Buelna, leída en medio del maremágnum de la cronística, era una más, entre las centenares de historias de nobles guerreros de la Edad Media. Tuvo que llegar el rescate de los historiadores del siglo XVIII, y en concreto de Eugenio de Llaguno, que la publicó, aunque despojada de largos fragmentos, en 1782, dentro de la prestigiosa colección crónicas auspiciada por la Real Academia de la Historia, para que se diera a conocer este texto singular y se rescataran algunos pormenores de la vida de un soldado representativo como pocos, o como nadie, de una faceta bastante insólita -la marinera- de la caballería europea del siglo XV.

En cuanto al autor de El Victorial, Gutierre Díaz de Games, se presenta al final del Proemio de la obra, poniendo de manifiesto su estrecha relación de dependencia hacia su señor Pero Niño, pero también su privilegiada posición de testigo fidedigno de "todas las más de las cavallerías..., ansí en armas como en amores", que narrará. Es el suyo un testimonio de autoría valiosísimo, y ciertamente excepcional en las letras medievales. Dice así:

E yo, Gutierre Díaz de Games, criado de la casa del conde don Pero Niño, conde de Buelna, vi deste señor todas las más de las 
cavallerías e buenas fazañas que él fizo, e fui presente a ellas, porque yo biví en su merced deste señor conde desde el tiempo que él era de edad de veinte e tres años, e yo de ál tantos poco más o menos. E fui uno de los que con él regidamente andavan, e ove con él mi parte de los travajos, e pasé por los peligros dél, e aventuras de aquel tiempo. (...) E fize dél este libro, que fabla de los sus fechos e grandes aventuras a que él se puso, ansí en armas como en amores (c. 8). ${ }^{1}$

Conservamos asimismo una preciosa cláusula al primer testamento de Pero Niño, de 1435. Describe minuciosamente cómo quiere que se labre su sepulcro en el coro de la iglesia de Santiago de Cigales:

1 Citaré siempre por la edición más divulgada de la obra, Rafae Beltrán (ed.): Gutierre Díaz de Games, El Victorial. Madrid: Taurus, 1994, especificando sólo la referencia a los capítulos, y modernizando ligeramente las grafías. Se puede consultar también, para una introducción más amplia y una anotación más completa del texto crítico, especialmente de las variantes textuales entre los diversos manuscritos a través de los que nos ha llegado El Victorial, mi editio maior (Salamanca: Univ. de Salamanca, 1997). Partí en ambas ediciones -el texto crítico es el mismo- de la base de la excelente edición de Juan de Mata Carriazo (ed.): Gutierre Díez de Games, El Victorial. Crónica de Pero Niño, conde de Buelna, por su alférez Gutierre Diez de Games. Madrid: Espasa-Calpe ('Colección de Crónicas Españolas', I), 1940. Gracias a la colación de todos los manuscritos conservados logré aclarar algunos pasajes y términos oscuros. Para un balance sobre la labor de Juan de Mata Carriazo como editor de crónicas, véase R. Beltrán, "Juan de Mata Carriazo, editor de crónicas medievales", en Juan Luis Carriazo Rubio (ed.): Juan de Mata Carriazo y Arroquia. Perfiles de un centenario (1899-1999). Sevilla: Universidad, 2001, pp. 59-109. Se encuentra en prensa, en la colección de Biblioteca Clásica que publica la Real Academia Española, una nueva edición, con revisión del texto crítico publicado en 1997 y anotación más pormenorizada y actualizada. Para el repaso biográfico que me propongo realizar en este artículo habré de basarme en parte de lo consignado en estas ediciones, aunque trataré de poner al día y adaptar la información, a partir de la nueva bibliografía publicada. Porque después de estas ediciones citadas, han aparecido numerosos trabajos sobre Pero Niño, la caballería y El Victorial. En el terreno histórico, hay que destacar el estudio de Alfonso Franco Silva, "El mariscal García de Herrera y el marino don Pedro Niño, conde de Buelna. Ascenso y fin de dos linajes de la nobleza nueva de Castilla", en La fortuna y el poder. Estudio sobre las bases económicas de la aristocracia castellana (s. XIV-XV). Cádiz: Univ. de Cádiz, 1996, pp. 499-542. Y en el literario, el trabajo de Cruz Montero Garrido, La historia, creación literaria: el ejemplo del Cuatrocientos. Madrid: Fundación Ramón Menéndez Pidal-Universidad Autónoma de Madrid, 1994; y la completa síntesis de Fernando Gómez Redondo, en su Historia de la prosa medieval castellana, vol. III: Los origenes del humanismo. El marco cultural de Juan II y Enrique III. Madrid: Cátedra, 2002, pp. 2350-2396. Así como los monográficos, varios de ellos publicados en Francia en torno al ańo 2000, de Anne-Marie Capdeboscq y Luis Fe Canto (eds.): La chevalerie castillane au XV siècle. $\grave{A}$ propos du "Victorial" de Gutierre Díaz de Games. Limoges: Presses Universitaires de Limoges, 2000; Jean-Pierre Sánchez (ed.): Lunivers de la chevalerie en Castille (Fin du Moyen Âge-Début des Temps Modernes). París: Du Temps, 2000, pp. 211-50; Ghislaine Fournes (ed.): L'univers de la chevalerie en Castille à la fin du Moyen Âge et au début des Temps Modernes (1369-1556). París: Messene, 2000, pp. 63-95; y Georges Martin (ed.): La chevalerie en Castille à la fin du Moyen Âge (Aspects sociaux, idéologiques et imaginaires). París: Ellipses, 2001, pp. 225-39. 
Puestos los losillos que yo he mandado faser e traer para mí e para la condesa mi muger, e que pongan delante e detrás mis armas e de la condesa y alrededor de las tumbas las letras: don Pedro Niño conde de Buelna el qual por la misericordia de Dios mediante la Virgen Santa María su madre fue siempre vencedor e nunca vencido por mar e por tierra segund su estoria lo cuenta más largamente... ${ }^{2}$

Sigue detallando elementos del sepulcro. En el reparto de bienes, destina una heredad, o en su defecto 3.000 dineros para su alférez Díaz de Games, que está escribiendo el libro de su historia (es decir, El Victorial). Y éste es el destino que ordena para el libro:

Mando que el libro de mi historia, que lo hace Gutierre Díaz de Games, que lo tenga la condesa en su vida, y, después que ella fallesciere, que lo pongan en la sacristía mía de la iglesia de la mi villa de Cigales, en el arca del tesoro de la dicha iglesia, y que no le saquen para ninguna parte; pero quien quisiere leer en él, mando que den lugar a ello.

Insisto desde el principio en el encargo de la biografía del conde, El Victorial, a Gutierre Díaz, porque, si bien no es el único, sí es el más importante y rico documento que conservamos de la vida de Pero Niño. Y quiero destacar también desde un primer momento el hecho de que la literatura, aunque sea ficción -que en este caso, además, no lo será, salvo en algunos pasajes muy esporádicos- forma parte plena de la documentación histórica, al dejar testimonio fehaciente no sólo de lo que se construyó en piedra duradera en el pasado, sino de algo mucho menos inasible, mucho menos inaprehensible, pero igualmente importante. La literatura es, como tantas veces, una de las más palpables evidencias de lo que se pensó, habló, imaginó, soñó, idealizó, sintió..., o de lo que más emocionó y motivó a nuestros antepasados.

La biografía o crónica particular de Pero Niño, El Victorial, tiene un enorme interés literario: no sólo destaca como la primera verdadera biografía de las letras españolas, sino que está escrita con un estilo elegante, de enorme fuerza y viveza de expresión. De nuevo, interés histórico a través de la historia del arte. Porque se pinta en El Victorial un retablo multiforme, compuesto, como en el mejor tapiz del gótico florido, por deliciosos cuadros de vida caballeresca, real e imaginaria.

2 Publicó el testamento Ángel González Palencia, "Don Pedro Niño y el condado de Buelna”, en Boletín de la Biblioteca Menéndez Pelayo, XVIII (=Homenaje a don Miguel Artigas, vol. II) (1932), pp. 105-46 [cito por separata numerada, pp. 1-43]; reproducido en su Moros y cristianos en España medieval. Madrid: CSIC-Instituto Antonio de Nebrija, 1945, pp. 274-324. 
Las damas inalcanzables y altivas de las canciones trovadorescas, los reinos remotos-repletos de maravillas entre lo real y lo imaginario- de las leyendas artúricas, los mares bravíos y los piratas feroces del Mediterráneo legendario de Odiseo y Eneas se dan cita, aunque pueda parecer mentira, en esta verdadera y totalmente fiable historia de la Castilla del siglo XV. Y la mejor prueba de ese historicismo, y hasta realismo casi costumbrista, está en que hallará el lector impagables noticias sobre la vida marinera cotidiana del Medievo, noticias que llegan a través de un rico y muy exacto lenguaje de la marinería, usado por alguien que había convivido y estaba acostumbrado a la práctica de su "parla marinera", convirtiendo el texto de El Victorial en verdadero antecedente de los "diarios de a bordo" colombinos.

¿Cómo se pueden presentar fundidos y hasta en armonía esos elementos aparentemente antitéticos, es decir, la más objetiva descripción histórica al lado de las más increíble fantasías? No es una combinación nueva y basta leer y ver en el cine las constantes reapariciones y recreaciones biográficas de grandes personajes históricos, pero también legendarios, desde Jesucristo hasta Alejandro Magno. ${ }^{3}$ Pero sí fue novedoso el experimento a principios del siglo XV, como lo estaba siendo en la escultura y la pintura el logro de un retrato independiente para la nobleza y, no digamos, para la burguesía. Por eso, sin dejar de ser biografía, la de Pero Niño es un panegírico novelado, el dibujo idealizado de una persona de carne y hueso sublimada a personaje heroico. En el espejo de la obra habremos de calibrar hasta qué punto ha quedado reflejada la figura del noble, pero también la imagen simbólica del mundo que pudo haber compartido con él buena parte de la aristocracia hispánica de su tiempo. Pero, insisto, no cabe dudar de la esencial veracidad de los hechos históricos que narra y que atañen a Pero Niño, con lo que ganamos un precioso testimonio de lo que fue la tensión entre vida real e ideal caballeresco "victorial" (es decir, victorioso) en el siglo XV europeo.

3 El Victorial, de hecho, se abre con un amplio Proemio, entre doctrinal e histórico, que pretende justificar la novedad de la escritura biográfica. Hay en él una apretada síntesis histórica de lo que sería la creación de la nobleza caballeresca desde la gentilidad hasta el cristianismo, y para representar a la caballería pagana son resumidas las vidas de cuatro príncipes de fama: Alejandro, Salomón, Nabucodonosor y Julio César. Mas el ideal caballeresco de la gentilidad es insuficiente. Pero Niño pertenecerá al nuevo ideal de caballería cristiana, que armoniza gloria mundana y galardón supremo. Para el Proemio, véase Ronald E. Surtz, "Díez de Games' Deforming Mirror of Chivalry: the Prologue to the Victorial”, Neophilologus, 65 (1981), pp. 214-18; María Mercedes Rodríguez Temperley, "El prólogo de El Victorial: heterogeneidad y orden a favor de una adecuada recepción”, Letras, 40-41 (=Studia Hispanica Medievalia, V) (1999-2000), pp. 90-99; y Jesús D. Rodríguez Velasco, "El libro de Díaz de Games", en La chevalerie en Castille..., pp. 211-23. Para el caso concreto de Alejandro Magno en el Proemio, R. Beltrán, "Huellas de Alejandro Magno y del Libro de Alexandre en la Castilla del siglo XV: un modelo para la historia y la biografía", en Catherine Gaullier-Bougassas (ed.): L'historiographie médiévale d'Alexandre le Grand. Turnhout: Brepols, 2011, pp. 155-72. 


\section{El linaje de Pero Niño}

Pero, ¿quién fue Pero Niño? El linaje remoto paterno es difícil de discernir. Eugenio de Llaguno ya señalaba la existencia de dos opiniones sobre el origen y derivación del linaje de los "Niño": la de quienes, empezando por el mismo Gutierre Díaz, defendían el origen en la casa real de Francia y la de quienes lo remontaban al propio rey Alfonso X. Toda opinión que dé crédito al linaje francés de los "Niño" fía exclusivamente de las palabras de Gutierre Díaz en El Victorial: "Este cavallero Pero Niño fue muy generoso de amas las partes. De parte de su padre viene de la casa real de Francia, de la casa de Anjou" (c. 9, p. 213).

Pero la primera mención confirmada de la familia de los Nińo procede de mediados del siglo XIV, y la hallamos en el Becerro de las Behetrías. El recuento nos presenta a los Niño como naturales en algunos dispersos lugares, pequeños hidalgos de pocos vasallos y escasas propiedades. No es un linaje de "condes" ni de "ricos-hombres" del que se pudiera jactar Pero Niño, como hace su biógrafo. O bien Gutierre Díaz está distorsionando la verdad abiertamente, o bien se está refiriendo a una época más antigua, sobre la que no tenemos suficiente información. Esta segunda quizás sea la suposición más razonable porque, en efecto, es más de medio siglo antes cuando encontramos, aunque nunca en el vecino reino francés, los únicos datos que permitirían dar cierto pábulo a las palabras del autor.

Dichos datos -la segunda opinión, a la que alude Llaguno- se refieren a la existencia de un Alfonso Fernández, hijo natural nada menos que del rey Sabio, Alfonso X. Este Alfonso Fernández es apellidado "el Nińo" en varias ocasiones por el autor de la Crónica de Alfonso X. ${ }^{4}$ Sólo aceptando esta procedencia que, hoy por hoy, parece la más plausible explicación al apellido "Niño", podríamos acoger sin tanto escepticismo -puesto que un gran señor llegó a ser aquel hijo de ganancia del rey- la contundente afirmación de Gutierre Díaz: “...aún se falla oy en día en escripturas en Castilla cómo en este linaje ovo conde e ricos-hombres".

La línea doblemente ilegítima ${ }^{5}$ podría también explicar el descenso del linaje de los Niños hasta la situación nada triunfal de pequeños hidalgos, poco o nada

4 En el c. LII de la Crónica se menciona a "Alonso Ferrandez, mi fijo" y se nos dice que "era ome de muy grand facienda é lo amaba mucho el Rey", y en el c. LXXV se ratifica que el hijo era "de ganancia”, es decir, ilegítimo, y que era señor de Molina. El señorío de Molina lo alcanzó Alfonso Fernández por consorcio con doña Blanca Alonso, señora de Molina, hija del infante don Alfonso de Molina (hermano del rey Fernando III). Del matrimonio sólo nacieron dos hijas. Una de ellas murió sin sucesión, y la segunda sin siquiera haber contraído matrimonio. Sin destinatario directo, el señorío de Molina fue cedido por doña Blanca a su hermana doña María de Molina, mujer del rey don Sancho, pasando así a la corona.

5 Porque para proceder Pero Niño de aquella rama habríamos de suponer que el hijo natural de Alfonso X tuvo descendencia extramatrimonial, puesto que las dos hijas legítimas de aquél, como acabamos de ver en la nota anterior, no dieron progenie. 
poderosos, en la que encontramos a la familia en el Becerro de las Behetrías. ${ }^{6}$ Allí hallamos a Juan Fernández Niño, seguramente el mismo Juan Niño, bisabuelo de Pero Niño, cuya muerte en el sitio de Algeciras (1342) mencionan tanto la Crónica de Alfonso XI como el Poema de Alfonso XI, 2.150-51, en los versos que siguen:

\author{
Fueron un día (a) asentar \\ engeños en un otero: \\ por los engeños guardar \\ mataron un escudero. \\ Johán Nińo fue llamado, \\ que al rey muy bien servió: \\ del buen rey hera criado, \\ en su serviçió morió (estrs. 2150-2151).
}

Sería éste el padre de Pero Fernández Niño, y Pero Fernández el abuelo de Pero Niño. Aunque Gutierre Díaz no menciona la heroica muerte de aquel bisabuelo en servicio y defensa del rey, sí realiza un comentario histórico muy interesante sobre el abuelo de Pero Niño, Pero Fernández Niño, que constituye una atrevida y sólo hasta cierto punto incomprensible toma de posición ante el empecinado y leal petrismo de Pero Fernández Niño: "Este don Pero Fernández fue siempre con el rey don Pedro fasta que murió. E después de su muerte, nunca quiso obedescer al rey don Enrique. Él e otros cavalleros fueron de aquella opinión, e salieron del reino. E aunque él no salió del reino, siempre duró e tovo en su intención, e puso sus travajos fasta que murió" (c. 18).

Las noticias que tenemos suyas confirman, en efecto, al personaje como un oficial de prestigio al servicio de la corona, aunque también fiel, antes cronológicamente que a ésta, a la casa de Lara, justamente la más poderosa enemiga de los reyes Alfonso XI y Pedro I. Pero volvamos a la declaración anterior. Pero Fernán-

6 En G. Martínez Díez (ed.): Libro Becerro de las Behetrías. León: Centro de Estudios e Investigaciones San Isidoro de León, 1979, "Los Ninnos" aparecen naturales de Espinosa, en Santander (n $n^{\circ}$ 217); "los fiios de Iohan Ferrandez el Ninno", en Castriello del Río Pisuerga (no 42) y Zarzosa del Río Pisuerga (no 43), en Burgos; un "Fernando Díaz, fiio de Iohan Ferrandez el Ninno de la Foieda", en la hoy despoblada Polvoreda, obispado de Palencia (no 19); y "Pero Ferrandez el Ninno", en Montuega, obispado de Burgos ( $\mathrm{n}^{\circ} 11$ ).

7 Sabemos que en 1350 era alcaide por Oropesa (Toledo), villa de Juan Núñez de Lara, IV de este nombre. No contamos con más noticias suyas hasta 1364, cuando lo encontramos como teniente y alcaide en la guerra del rey Pedro contra su homónimo aragonés. Dos albalás y una carta lo presentan como adelantado del reino de Murcia (en sustitución) y alcaide de Alicante. Véase Luis Vicente Díaz Martín, Itinerario del rey don Pedro I. Valladolid: Univ. de Valladolid, 1975, pp. 114-19 (docs. 856, 859, 860, 864, 865, 866 y 869); y del mismo autor, Los oficiales de Pedro I de Castilla. Valladolid: Univ. de Valladolid, 1975, p. 31, y "Los maestres de las órdenes militares en el reinado de Pedro I de Castilla”, Hispania, XL (1980), pp. 285-386, esp. pp. 326-30. Los vasallajes a 
dez Niño, dice el libro, "nunca quiso obedescer al rey don Enrique", a quien se opuso con todo su esfuerzo, fiel al recuerdo del rey asesinado, viviendo en exilio interno hasta su muerte. ${ }^{8}$ El padre de Pero Niño, Juan Niño, sufrió negativamente, como es lógico, las consecuencias del vuelco político y del empecinamiento de su padre. Su nombre no consta ya, como el de éste, entre los de la oficialidad real, aunque sabemos que luchó para la corona. Prácticamente las únicas noticias sobre su vida que poseemos nos las proporciona El Victorial. ${ }^{9}$ Natural en la hoy desparecida Villagómez, sus inicios junto al rey Pedro I no podían haber sido más prometedores: fue "un cavallero criado en la casa del rey" (p. 231). Al rey acompañó, como doncel, a Bayona, en 1366, y al rey defendió en el cerco de Montiel, en 1369, donde "le armava muy fuertes ballestas" (p. 226). E incluso muerto éste, mantuvo su causa, a las órdenes de Martín López de Córdoba, en el cerco de Carmona. Con la muerte del rey y la proscripción de su padre, su fortuna cambiaría radicalmente. El Victorial nos cuenta un incompleto capítulo de su enemistad con unos vecinos que "eran favorescidos, ansí de privados del rey como de otros ca-

Juan Núńez de Lara y al rey habrían sido ciertamente contradictorios de haberse simultaneado. Sin embargo, median casi quince años entre uno y otro. Además, tengamos en cuenta que la amenaza de los Lara termina con la muerte, primero, del propio Juan Núñez, a finales de 1350 (Crónica de Pedro I, 1350, c. XIV, p. 410), y un año después del último vástago de la familia, el pequeño Nuño de Lara, que había huido a Vizcaya con su madre (ibid, 1351, c. X, p. 416). Pudiera haber existido una relación entre este servicio a la casa de Lara, y el matrimonio de Isabel de Molina, la hija de Alfonso Fernández Niño, con Juan Núnez ("Crónica del rey don Sancho el Bravo", en Crónica de los Reyes de Castilla, c. VII, p. 84). De hecho, en 1373, nos cuenta Pero López de Ayala, Crónica de Enrique II, 1373, c. X, pp. 18-20, cómo dońa María, condesa de Alenzón, hermana del citado Juan Núñez, reivindicaba ante Enrique II la propia Oropesa, pero también precisamente, junto a otros muchos, los lugares de Cigales, Berzosa y Fuente Bureba (en la Merindad de Bureba), que Juan I concedería pocos años más tarde, en 1386, junto con Cigales (en el infantazgo de Valladolid) al padre de Pero Niño, Juan Niño, como agradecimiento por los servicios prestados por él y por su esposa en la crianza del futuro Enrique III.

8 ¿Por qué Gutierre Díaz no oculta, sino al contrario, hace alarde de la postura oposicionista del abuelo frente al primer rey Trastámara? En mi opinión, está sugiriendo que si el linaje de Pero Niño, ligado a la suerte del rey depuesto, estuvo a punto de sucumbir, de perecer tras su -supuestaantigua grandeza, no fue por culpa de sus miembros, sino por los reveses de la alta política. Gutierre Díaz pretende que el lector infiera que mantener un valor noble por excelencia -su fidelidad al rey Pedro- había estado cerca de causar la perdición a Pero Fernández Niño y a sus descendientes. El "Cuento de los reyes" Pedro I y Enrique II, que no es otra cosa que el relato del cambio de un orden, la sustitución de un rey por otro a través de los episodios principales de la guerra civil, sirve para que el autor pueda interpretar a su conveniente antojo las repercusiones en una familia particular (los Niño) de un hecho político: "Este Cuento de los reyes he traýdo (...) por mostrar el linaje de Pero Niño, de quien este libro fize, cómo abaxó de como ante avía seýdo, por la buelta de los reyes" (c. 17). Véase más ampliamente en R. Beltrán, "El 'Cuento de los Reyes' Enrique II y Pedro I: una historia-exemplum sobre la caída de los linajes", Boletín de la Real Academia Española, LXIX (1989), pp. 417-57.

9 Otorgó testamento el 6 de mayo de 1385, en Cigales. Otros hijos de su matrimonio con Inés Lasso fueron Alfonso Niño, Juana Lasso y Mencía Niño. 
valleros grandes del reino", del que se deduce una situación muy comprometida, en una época en la que la aceptación del nuevo orden era la tónica dominante. Ante ese episodio de enfrentamiento con los "favorescidos y privados", como ante la obstinada proclamación del petrismo de Pero Fernández Niño, intuimos que Gutierre Díaz carga las tintas intencionadamente sobre el victimismo del padre y abuelo. Los hechos históricos no hacen pensar en una oposición tan furibunda y orgullosa del padre al poder real, pues su matrimonio con Inés Lasso requirió a buen seguro la mediación y aquiescencia de personas poderosas. ${ }^{10} \mathrm{El}$ objetivo, de nuevo, sería insistir en la vinculación de la familia Niño con el régimen derrotado, con el fin de justificar la baja situación económica familiar en los inicios de la carrera de Pero Niño. ${ }^{11}$

El Victorial nos presenta a Juan Niño, además, luchando para el rey Trastámara en el asedio de Lisboa. Pasados varios años desde Montiel y Carmona, ha tenido que asumir su condición de militar al servicio de la corona. Finalmente, estará la aceptación -a regańadientes, según nos la presenta Gutierre Díaz- de la solicitud de la reina madre para que su mujer, Inés Lasso, amamante al recién nacido infante, el futuro Enrique III. Este capítulo, brillantemente aprovechado por Gutierre Díaz en la biografía, a causa de sus potencialidades folclórico-literarias, será el hecho que más importantes consecuencias económicas traerá para la familia, pues supondrá un considerable premio en metálico y en mercedes.

En resumidas cuentas, el pretendido linaje de condes y ricos-hombres, ya fuera el ilocalizable -y sospechoso de falaz- linaje francés que nos propone Gutierre Díaz, ya el que se remonta al hijo de ganancia del rey Sabio, había descendido con el tiempo hasta los humildes hidalgos, oficiales profesionalizados, que habían sido el bisabuelo, el abuelo, el padre de Pero Niño, y que sería el mismo Pero Niño hasta la concesión del condado. La estrategia de Gutierre Díaz consiste en no dejar resquicio para que se planteen dudas sobre lo que expone con autoridad de testigo. Da por descartada la necesidad de justificar una ascendencia casi legendaria (la de la casa de Anjou) y se afana, en cambio, en justificar que el descenso de esas alturas no se debió a deméritos propios, sino a la caída de los reyes por vaivenes políticos.

\section{Nacimiento, crianza y educación de Pero Niño (I 378 -I 394)}

Uno de los primeros meses de 1378 nació Pero Niño. Deducimos la fecha a partir de El Victorial: "En aquel tiempo que dońa Ynés Lasa tomó a criar al rey don Enrique, avía su fijo Pero Niño un año e medio" (c. 22, p. 242). El hijo de

10 Para el linaje de Inés Lasso, véase el trabajo de Norah B. Ramos, "La decadencia de la Abadía de Covarrubias en la Baja Edad Media. Notas para su estudio", Cuadernos de Historia de España, LXV-LXVI (1981), pp. 431-48.

11 Véase Cecilia Devia, "La lucha fratricida en el "Cuento de los reyes" (El Victorial) y en las 'Crónicas' del Canciller Ayala”, Anuario de estudios medievales, 40/1 (2010), pp. 387-413. 
Juan I y Leonor de Aragón, el futuro Enrique III, nació el 4 de octubre de 1379, luego no es difícil descontar los dieciocho meses aproximados. Cuando nacía un príncipe, o hijo de gran señor, se le debía proveer de una o dos nodrizas sanas, de buenas costumbres y de linaje. Es lo que va a ocurrir con el príncipe Enrique, tal como nos cuenta $E l$ Victorial. La abuela del recién nacido fue la encargada de buscar ama joven, sana y de linaje. La suerte recayó en Inés Lasso, sobre la nobleza de cuyo linaje no cabía la menor duda. Hay en todo el episodio un intento de justificar la aceptación del encargo por parte de los padres de Pero Niño. Contra lo que en principio pudiera parecer, no significaría un honor, sino cierto desdoro, tal como deducimos de las palabras de Gutierre Díaz: "enclináronse a su mandado, e sacando condición que la non llamasen ama, como a las otras, e la tuviesen en otro estado, mayor e de otra mayor guisa, más que nunca otra mayor ama fuera tenida" (p. 233).

Así, pese a que Gutierre Díaz insiste en que "ellos solos eran escogidos en todo el reino para criar el príncipe", la primera reacción de Juan Niño había resultado aparatosamente negativa: "non pudiendo mudar la voluntad del rey e de la reina, fuéronse de la corte, e tomaron camino para se yr a Aragón". El propio rey, a decir de Gutierre Díaz, envió por ellos y los hubo de convencer con argumentos y mercedes. La tarea de la nodriza solía durar tres años. Cumplidos éstos, se retiraba, por lo general generosamente recompensada. Es el caso de Inés Lasso, a quien "diéronla tal galardón, qual nunca fue dado a otra ama que rey criase en Castilla, que montaron sus heredades e dádivas, en villas e en mercedes, en cuantía de cinquenta mil florines" (p. 233). Las villas a las que se refiere Gutierre Díaz han de ser las de Cigales, Berzosa y Fuentebureba, que fueron concedidas el 26 de diciembre de 1382.

El servicio de la madre de Pero Niño favorecería que el niño se criase en la casa real; allí transcurrirían, en ocasiones seguramente como compañero de juegos del propio príncipe, sus diez primeros años. El privilegio de Juan Niño de poder criar a su hijo junto al príncipe era ambicionado por todo magnate, aunque la mayoría había de conformase con la crianza junto a un noble favorecido en la corte. Alfonso XI había institucionalizado la entrega del infante a un ayo, hidalgo de padre y madre, al cumplir tres años, es decir acabada la crianza maternal. La costumbre sería adoptada imitativamente por la nobleza. El ayo, con el que se tenía relación estrecha y prolongada, tomaba afectiva y prácticamente el lugar de la figura paterna. El condestable Ruy López Dávalos, aunque nunca se hable de él como ayo, ocupará ese lugar simbólico respecto a Pero Niño.

La figura del ayo va vinculada asimismo al período de instrucción teórica, que podía empezar hacia los seis años con la enseñanza de las primeras letras y que a los catorce años se daba por perfectamente cumplida para la nobleza. Ese inicio se retrasa, sin embargo, a los diez ańos en El Victorial. Gutierre Díaz nos asegura que: "quando Pero Niño ovo diez años, fue dado a criar a a enseñar a un hombre 
sabio e entendido, para que lo enseñase e dotrinase en todas las buenas costumbres que pertenecen aver a fidalgo bueno e noble. E enseñávale en esta guisa..." (p. 234). Estaba detrás la imagen de Aristóteles dando lecciones a su discípulo Alejandro Magno, en el Libro de Alexandre, una obra cuyos versos cita el autor, demostrando conocerla muy bien; detrás también -¿por qué no?- la imagen del caballero Zifar haciendo lo propio con sus dos hijos, Garfín y Roboán, en el Libro del caballero Zifar. De hecho, a renglón seguido, El Victorial incluye una suerte de catecismo o doctrinal resumido (cs. 19-20); compendio que, si no podemos aceptar como traslación exacta de la enseñanza que se daba al niño, sí es indicativo de la orientación ideológica de la misma. Y este catecismo llena el espacio narrativo que corresponde a los cuatro ańos de tiempo biográfico de lo narrado: "ansí fue criado este donzel, e lo crió e dotrinó este buen hombre, fasta el tiempo que ovo catorze años" (p. 242). ${ }^{12}$

\section{Las Primeras armas de Pero Niño (I 394-I399)}

Contando con quince o dieciséis años tenemos ocasión de ver reflejada la actuación de un Pero Niño adolescente, iniciándose en sus primeras lides. Estas tienen lugar en dos de los sitios o cercos puestos a Gijón, plaza del tío del rey, don Alonso Enríquez, conde de Noreńa, último episodio de los enfrentamientos entre sectores de la nobleza durante la minoría de Enrique III. El primero ocurre en septiembre de 1394 (cs. 22-23) y el segundo en julio de 1395 (cs. 26-27); en ambos, el contexto general es reflejado con exactitud por Gutierre Díaz, y sirve de marco a las acciones en las que despiertan el valor y la fama de Pero Niño. Gutierre Díaz incluye también un viaje del rey a Sevilla para apaciguar los ánimos de los banderizos, que habían concluido con el saqueo de la judería de la ciudad, y que se dio entre octubre y noviembre de 1395; nos cuenta Gutierre Díaz dos curiosas proezas del muchacho durante su estancia en Sevilla: la matanza de un jabalí y el golpe de espada que atesta a la gruesa maroma de un aparejo de pesca que ponía en peligro de zozobra la barca del rey; despunta asimismo Pero Niño en las fiestas sevillanas de cańas y toros.

De 1496 a 1399 vamos a hallar al doncel Pero Nińo en la guerra con Portugal. En mayo de 1396, y ante el impago por parte de los castellanos de una fuerte indemnización estipulada en los pactos derivados de Aljubarrota, los portugueses habían conquistado Badajoz como medida de fuerza para posteriores negociaciones. Las tropas castellanas realizaron por su parte importantes ataques de represalia: López Dávalos, que todavía no había recibido el título de condestable, pe-

12 Estudiamos el contenido doctrinal de estos "castigos" y sus fuentes, en R. Beltrán y M. Haro, "Las fuentes de las enseñanzas a Pero Niño en El Victorial", Scriptura, 13 (1997), pp. 227-51; estudio revisado y ampliado por los mismos autores en "Las enseñanzas a Pero Niño y la literatura de castigos en El Victorial', en Antonia Martínez (ed.): Homenaje a Fernando Carmona. Murcia: Univ. de Murcia (en prensa). 
netró hasta Viseo y la incendió. Y en Viseo vuelve a aparecer Pero Niño, tutorado por Dávalos. Allí, alentado por la osadía e ingenuidad de sus pocos años, desafiará a un avezado contrincante portugués. En mayo de 1398, Juan I de Portugal cruza el Miño con un poderoso ejército, y cerca Tuy. Su aliado, el arzobispo de Santiago, apoya la acción, haciéndose fuerte en Pontevedra. Allí encontraremos, algo después de julio (cuando Tuy se rindió), a Pero Niño escaramuzando, retratado de manera entre bélica y festiva, como en una ficción caballeresca (c. 29).

Tras los éxitos portugueses de Tuy y Pontevedra, se llegó a una tregua de seis meses (febrero a julio de 1399). Al finalizar ésta, el rey portugués tomó la iniciativa al atacar la formidable fortaleza de Alcántara. Ruy López Dávalos trajo refuerzos y el enemigo levantó el campo. El mismo 1399, en julio, se tomarían las plazas de Peñamoncor y Miranda. Pero Nińo participa en estas campańas (cs. 3536), y Gutierre Díaz nos cuenta cómo en esta última plaza derribó a un enemigo, disparándole una "piedra puñal". ${ }^{13}$

Pero la narración histórica, antes de ocuparse de la participación de Pero Niño en la defensa de Alcántara, y en las tomas de Penamacor y Miranda, se ha visto interrumpida para darnos noticia de su primer matrimonio (c. 33), probablemente celebrado en el invierno de 1398-1399. Gutierre Díaz dice que este matrimonio "fue fecho por trato de amores". Hemos visto a Pero Nińo caminar en Galicia y Portugal al amparo de Ruy López Dávalos. Sus vínculos se estrechan todavía más gracias al enlace con Constanza de Guevara, sobrina del Canciller Pero López de Ayala, joven viuda de Diego de Velasco y hermana de dońa Elvira, casada con Dávalos. Para ambas, Constanza y Elvira, escribió sendas cantigas uno de los principales poetas del Cancionero de Baena, Alfonso Álvarez de Villasandino. La de loor a Constanza sería encargada por el propio Pero Nińo y escrita a poco de casarse, pues habla con naturalidad de esa transición de doncella a casada: "Quando yo vos vi doncella / de vos mucho me pagué; / ya dueña vos loaré". Juega a la adivinanza fácil con el enigma de una ciudad alemana homónima (Constanza): "Los que vuestro nombre quieren / saber, sepan por verdat / que la costa [el gasto] que fizieren / por saber certenidad / perderán si no sopieren / las letras de una cibdat, / la qual non les nombraré". ${ }^{14}$

Doña Constanza moriría a los cuatro o cinco años, es decir, hacia 1403 o 1404, poco antes de la salida de Pero Niño en campaña por el Mediterráneo.

13 Véase R. Beltrán, "De la crónica oficial a la biografía heroica: algunos episodios de Pero López de Ayala y Alvar García de Santa María y su versión en El Victorial”, en Vicente Beltrán (ed.): Actas del I Congreso de la Asociación Hispánica de Literatura Medieval. Barcelona: PPU, 1988, pp. 177-85.

14 Véase mi trabajo, "La presencia de Pero Niño, conde de Buelna, en el Cancionero de Baena", en José Luis Serrano Reyes y Juan Fernández Jiménez (eds.): Juan Alfonso de Baena y su "Cancionero". Actas del I Congreso Internacional sobre el "Cancionero de Baena" (Baena, del 16 al 20 de febrero de 1999). Baena: Ayuntamiento, 2001, pp. 3-14. 
Pero Niño tuvo con ella un hijo, de nombre Pedro, que murió a los veintisiete años. El breve tiempo de matrimonio coincide con el silencio de El Victorial sobre los acontecimientos de esos ańos, si bien es cierto que tampoco hubo durante ese período actividad bélica a la que pudiera ser llamado el futuro conde de Buelna.

\section{La campaña del Mediterráneo (I 404-I 405)}

En la segunda parte de El Victorial, en la que nos detendremos con algo más de detalle, se cuentan las expediciones que como capitán de la flota castellana realizó Pero Niño: en primer lugar por el Mediterráneo, desde la costa africana hasta Italia y Cerdeña, en 1404, en razzia policial contra los corsarios que atacaban las naves comerciales castellanas; y durante los dos años siguientes, en 1405 y 1406, por el Atlántico, contra la flota y costas inglesas, en apoyo a la marina francesa y dentro de la política de alianzas con Francia del rey Enrique III de Castilla. La confrontación con otras crónicas coetáneas y con documentación no hará más que poner de relieve la veracidad esencial de unos acontecimientos históricos muy amenamente narrados en El Victorial.

La campaña del Mediterráneo tuvo lugar entre abril de 1404 y marzo de 1405. La expedición de Pero Niño era en principio misión de policía contra los corsarios cristianos que atacaban los barcos de comercio castellanos, pero llega a convertirse en muchos momentos en una campańa de verdaderos corsarios castellanos contra las costas africanas, puesto que en las propias acciones de Pero Niño se juntaron las labores de vigilancia con las de corso, con conatos de verdadera piratería. ${ }^{15} \mathrm{La}$ actividad comercial castellana había experimentado un espectacular aumento, en particular desde los puertos de Sevilla y Cartagena, desde donde Castilla exportaba lanas y tejido a Italia. Los monarcas se servían de los corsarios en tiempo de guerra, pero en tiempos de paz esta ayuda se volvía en su contra y constituía el principal peligro para el comercio marítimo. ${ }^{16}$ En medio de esta situación de inseguridad, Enrique III, presionado por la clase mercantil, hubo de tomar cartas en el asunto. Fue entonces cuando: "el rey llamó a Pero Niño e encomendole

15 El mejor estudio que tenemos para toda esta campaña se debe a M. ${ }^{a}$ Teresa Ferrer i Mallol, "Els corsaris castellans i la campanya de Pero Niño al Mediterrani (1404). Documents sobre El Victorial", Anuario de estudios medievales, V (1968), pp. 265-338; traducido, con actualización bibliográfica, como "Los corsarios castellanos y la campaña de Pero Niño en el Mediterráneo (1404)", en su Corsarios castellanos y vascos en el Mediterráneo medieval. ['Anuario de Estudios Medievales', Anejo 40]. Barcelona: Departamento de Estudios Medievales (Institución Milá y Fontanals, C.S.I.C.), 2000, pp. 9-98.

16 Los campos del corso y la piratería no están muy claramente delimitados. El corso disfrutaba de una más o menos encubierta protección oficial, mientras que la piratería, como en el mito romántico del libre corsario, era absolutamente incontrolable. Las campañas bélicas oficiales, al tiempo que legitimaron las acciones individuales del corso, fomentaron, incluso entre muchos miembros de la pequeña nobleza, unos hábitos de fácil ganancia que resultarían difíciles de abandonar. 
este fecho muy secretamente. Mandole aparejar en Sevilla galeas (...) que fuesen escogidos para ellas los mejores marineros (...). E otrosí fuertes remeros, criados de mar, e que fuesen bien avituallados. E otrosí, que fuesen buscados los mejores ballesteros, armadores e punteros...” (c. 37).

Pero Niño arma con estos poderes dos galeras y una nao, con un total de "treinta hombres darmas (...), que non podían en las galeas ir más". Se mencionan incluso los nombres de los dos patrones: "un cavallero antiguo, que llamavan micer Nicoloso Bonel, ginovés, muy sabidor de mar e buen marinero (...) e a Juan Bueno, cómitre de Sevilla”, que aparecen mencionados en otros textos cronísticos. La partida tuvo lugar hacia primeros de mayo de 1404. En Coria del Río recalaron, siendo convidados magníficamente por un sevillano, que les propuso culminar el ágape votando sobre un pavo real. ${ }^{17}$ De Coria van a Sanlúcar de Barrameda, ya en la desembocadura del Guadalquivir; de allí a Cádiz, y pasando por Santi Petri embocan el estrecho de Gibraltar hasta Tarifa.

Luego de hacer noche al este de Tarifa, siguen hacia Algeciras y Gibraltar. Aceptan la invitación de los moros, de quienes reciben "adiafas" o presentes, "ca entonces avían ellos treguas con Castilla”, treguas que iban a durar hasta 1405 . Málaga es descrita, y frente a ella los marineros se ven espantados por una "niebla escura" o "escurana", como es llamada más adelante y como también la llama Cristóbal Colón en el diario de su primer viaje. En Málaga reciben más agasajos y tienen oportunidad de descender para visitar "la casa de los ginoveses e a mirar la judería e la tarazana”. De Cartagena saltarán ya a la costa de Berbería. El primer raid o incursión militar en la costa no tuvo más hecho digno de nota que el desembarco en una aguada, las cuevas de Alcocébar, donde recalarán también más adelante (c. 50). Tiene lugar una insignificante escaramuza que Gutierre Díaz hincha con entusiasmo -incluyendo una espontánea conversión religiosa-, siquiera sea para mitigar el decepcionante resultado de la incursión. Al no encontrar navíos moros, regresan a Cartagena (c. 38).

La siguiente salida persigue la captura del corsario Juan de Castrillo, que tenía una oscura historia delictiva tras de sí, y que navegaba junto con el mallorquín Arnau Aymar, ambos al servicio de Benedicto XIII. Y hasta Marsella, donde estaba el Papa Luna, sigue Pero Niño en pos de ellos. El estrecho puerto posee un ingenioso sistema de banderas, que avisa a los corsarios de la llegada de las galeras. $\mathrm{Al}$ intentar salir a mar abierto, y cuando Pero Nińo les ataja la escapada con sus

17 Gutierre Díaz pretendería hacer recordar las grandes despedidas literarias, con una alusión a la ceremonia exótica de los votos del pavón, que se remontaban a los Voeux du Paon de 1306, precedentes de los más famosos Voeux du Faisan, ofrecidos por Felipe el Bueno y sus caballeros, en 1454. Véase, sobre el episodio en su contexto histórico-literario hispánico, Amaia Arizaleta, Rafael Beltrán y Francisco Bautista, "L'héritage espagnol des Voeux du Paon", en Catherine Gaullier-Bougassas (ed.): Les Voux du Paon de Jacques de Longuyon: originalité et rayonnement. París: Klincksieck, 2011, pp. 237-52. 
rápidas galeras, realizan los corsarios una maniobra, "un arte". Simulando preparativos para luchar, y obligando a los castellanos a hacer otro tanto, aprovechan ese momento para huir con mayor ligereza. Pero Nińo y los suyos se encuentran entonces metidos en las fauces de un lobo desconocido. Gutierre Díaz consigue mantener una inquietante tensión a la espera del desenlace feliz: la múltiple perspectiva desde la que son contempladas las maniobras de las naves; la negociación con el emisario del Papa, con sus idas y venidas; el mandato de Pero Nińo a los suyos para que mientan, si quieren quedar salvos del mal paso... Finalmente, salen del apuro y Pero Niño es aceptado e invitado, aunque cae unos días enfermo allí.

Los corsarios han huido hacia Cerdeña, aprovechando la postración de Pero Niño, pero éste, cuando recibe la noticia, parte raudo en su persecución, "como el águila que va buscando la prea quando á voluntad de comer". En la travesía sus naves son sorprendidas por una tormenta, que Gutierre Díaz describe con viveza y realismo (es la primera tormenta descrita en El Victorial; pero hay otras buenas descripciones en los cs. 47 y 89), aportando un vocabulario marítimo técnico y preciso, valiosísimo para la historia de la lengua y para la historia de la navegación.

Tras un descanso en Capraia (la "Cabrayra" del texto), prosiguen la persecución hasta Alguer. El capitán de la plaza, por entonces todavía aragonesa, convence a Pero Niño de que deje libres a los corsarios, pues realizaban una imprescindible labor de aprovisionamiento e incluso defensa de estos lugares lejanos. Gutierre Díaz menciona como de pasada, a continuación, la captura de otra nao en un puerto cercano, Oristano. En este incidente es muy probable que Pero Niño se extralimitara, porque tuvo notables consecuencias políticas, que Gutierre Díaz, desde luego, silencia, sin aportar más detalles, seguramente para evitar el recuerdo de un grave desaguisado. La estancia en Cerdeña habría tenido lugar entre el 8 o 9 de julio, y el 12, fecha atestiguada de la captura de Oristano.

Sigue el episodio central y principal de la campaña en el Mediterráneo: el ataque de Pero Niño a Túnez (cs. 42-44). Tras diez días de acecho en las islas vecinas de Zimbra y Zimbrot, se lanzan hacia el puerto, imprudentemente, durante una noche con "la luna muy clara". Aferran primero una galera fondeada a una legua del puerto. Se disponen a atacar una gran galera, pero el ruido de la batalla anterior ha puesto en alerta a una carraca de genoveses, que avisa a los tunecinos. Se produce una emocionante persecución entre galeras. Cuando la castellana embiste la mora, Pero Niño queda solo en ésta, haciendo retroceder a los enemigos, hasta que logra prender al arráez o capitán. Amaneciendo ya, acuden los suyos en auxilio, y pretenden tomar la galera, que sin embargo ha encallado. Mientras tanto, llegan desde tierra "más de diez mil moros", que ponen en peligro la galera castellana, de manera que han de abandonar la otra, sin poder capturarla (aunque saqueándola) y han de ser arrastrados in extremis por la otra galera. Hay un curioso intercambio de mensajes como epílogo del episodio (c. 45) y una descripción esmerada de la ciudad de Túnez (c. 46). Desde Túnez, correrán la costa de Bona 
y Bugía. Alcanzan una galeota de aragoneses, portadora de frailes trinitarios, que ya por entonces acudían al canje de cautivos. Capturan un cárabo de moros y regresan a Cartagena. Allí Pero Niño envía los prisioneros al rey, reparte el botín, cura de los heridos, repara las naves, repone armas y vituallas, y se dispone a una tercera y última incursión en Berbería, que tendrá lugar entre agosto y septiembre de 1404.

En esta tercera expedición se dirigen hacia Orán, y fondean en las islas Habibes, donde se mantienen en espera de avistar navíos enemigos. Al no pasar ninguno, Pero Niño se propone atacar un "aduar”, aldea de moros “alárabes" (según Gutierre Díaz, nómadas descendientes de moros españoles), y para ello envía un grupo de exploración por delante. El disgusto de Pero Niño es enorme cuando los expedicionarios no logran encontrar la aldea habitada, pese a todos los indicios de que estaban muy cerca de ella. Pero Niño endilga una dura reprimenda a los exploradores. Sin embargo, al día siguiente un moro capturado confiesa que el aduar que buscaban se hallaba tomado por un jefe "alárabe", que iba con mil quinientos hombres a caballo. El increíble hecho de no haber encontrado el "aduar" había sido, por tanto, no sólo providencial, sino milagroso.

Se desquitan del fracaso cuando encuentran la "alhorma" o campamento del "alárabe" Muley Aben Agí. La persecución que sufren los codiciosos hombres de Pero Nińo está plasmada con dramático verismo. Pese a la insistencia en que abandonen las presas más pesadas, dado el peligro inminente, el enemigo logra darles alcance. Ganan terreno y pueden recuperar parte del botín, al matar a uno de los principales moros. Sin embargo, hallándose a la vista de la playa, crece el número de atacantes; Pero Niño ha de disponer la defensa de una peña, y mantenerla todo el día con relevos de hombres. Pero Niño, al final, personalmente, desamparando las naves - "solas, encomendadas a Dios"-, logra salvar al grupo de los suyos cuando se encontraban ya en franco peligro. Gutierre Díaz sabe convertir la acción, de nuevo, en un emocionante capítulo novelesco.

Tras un desembarco breve y poco fructífero en una zona excesivamente poblada, rica en agricultura y minería, costean, asaeteando enemigos desde un bote, hasta Orán y Mers-el-Kebir, y alcanzan las cuevas de Alcocébar, aguada conocida de la primera incursión (c. 38). La llegada de los castellanos estaba más que avisada y, con todo, se hacía preciso recoger agua. La toma se hace con grandes dificultades, bajo el hostigamiento constante de un grupo de moros, en lo que sería algo más que una escaramuza. Y afortunadamente no caen en la tentación de perseguir a los atacantes hacia el interior, porque luego se descubre la celada que les estaba preparada: "fasta cinco mil de cavallo, más gente de pie [...] sin cuento" que les habrían acorralado sin remedio.

Por segunda vez las islas Habibes sirven de albergue, durante al menos veinte días, a la espera de una mejoría del mal tiempo otonal. Ante la escasez de provisiones, Pero Niño ordena un racionamiento estricto del pan, el agua y el vino. 
La carencia de agua se hace tan gravosa que han de arriesgarse a acudir a otra aguada, "cementerio de cristianos", en la que se libran por poco de la venganza de los moros. Finalmente, en contra de su voluntad, Pero Niño acata el consejo de regresar a Castilla que le da el cómitre Juan Bueno. Es verdaderamente increíble el pormenor del detalle en el relato de estos momentos, en los que se llega a plasmar hasta el manoteo o braceo explicativo de Juan Bueno.

En Cartagena encuentra Pero Niño una misiva del rey para que deje las galeras en Sevilla y regrese a la corte. En el camino a Sevilla todavía alcanzan una galeota de Aragón, que vacían totalmente, aun dejando libre después la nave, "segund que era derecho". Al parecer en este saqueo se funden dos acciones de Pero Niño calificadas de "piráticas" por la cancillería catalana, en protesta al rey castellano, y que dan perfecta noción del difícil límite entre la legalidad y la ilegalidad en toda la empresa de policía marítima de Pero Niño. Las heridas recibidas en el ataque a Túnez han sido graves, especialmente una en el pie que le ha impedido intervenir directamente en varias incursiones posteriores de los suyos, y que, a decir de la biografía, se cura él mismo. Una vez en tierra, Gutierre Díaz hace coincidir su viaje a la corte, en Segovia, con una nota referida al nacimiento del futuro Juan II, en marzo de 1405 (c. 51).

\section{La Campaña del Atlántico (i 405-I 406)}

No fue en la costa atlántica ni en la lucha contra Inglaterra, ciertamente, donde se fijaron con prioridad los intereses políticos y militares de estos dos últimos años del reinado de Enrique III. La fuerza moral que la paz ventajosa con Portugal había dado al rey no se transformó en hostigamientos contra Inglaterra -aunque las treguas con ella fueron cortas y frágiles-, sino en la renovación de la lucha contra Granada. Sin embargo, Enrique III, aliado de Francia pero ligado por su mujer, una Lancaster, al trono inglés, trataba de mantener una paz, aunque tensa, en toda la zona del Canal, ruta que los barcos castellanos efectuaban en su camino de La Rochela a Londres. Para Inglaterra comenzaba entonces la edad dorada de su piratería, que tendría como víctimas primeras a los castellanos. Frente a los ataques ya muy graves de 1402 y 1403, la secretaría de Enrique III presentó sus quejas y se movió en Londres, aunque inútilmente, dada la solidaridad entre los bucaneros para desobedecer las órdenes del monarca inglés de que se respetara el libre comercio. Uno de esos famosos piratas fue Harry Paye, señor de Poole, a quien veremos mencionado en varias ocasiones en El Victorial. Tras muchos de los envíos perdidos se hallaban personajes del peso de Diego López de Stúniga, o importantes firmas italianas, cuyos intereses eran gravemente lesionados. La economía arrastró a la política y se llegó a un estado de guerra a causa del comercio. El rey castellano quiso hacer una demostración de fuerza, e imponer un severo castigo a los ingleses, para lo que comprometió una amenazadora flota de cuarenta naves, al mando de Martín Ruiz de Avendaño, que no acometieron nunca, por 
lo que sabemos, acciones de guerra, a diferencia del celo mostrado por las tres activas galeras al mando de Pero Nińo. ${ }^{18}$ Lo cierto, sin embargo, es que los saqueos de Pero Niño de la costa de Cornualles, y especialmente del puerto de Poole (el puerto de Harry Paye) lo único que lograrían, a la larga, sería hacer todavía más insegura la navegación hacia Flandes.

A esta empresa envió el rey a Pero Niño. Sin más preliminares, Gutierre Díaz cuenta cómo las galeras de Pero Nińo hicieron camino hacia Pasajes, y de allí travesía hacia La Rochela. Tras cinco días de singladura, llegaron a la isla de Ré, frente a La Rochela, y luego al famoso puerto. En él se encontró Pero Niño con mosén Charles de Lebret, condestable de Francia desde 1402. Pero Niño se dirige desde La Rochela a Burdeos, saqueando, robando y quemando zonas de sus alrededores en manos inglesas (c. 65). De nuevo en La Rochela, tiene lugar un encuentro importante para Pero Niño, esta vez con Charles de Savoisy, influyente señor francés por entonces desterrado de la corte. Se pusieron de acuerdo para navegar en compañía, puesto que sus objetivos de acoso y saqueo de naves y puertos ingleses eran en gran parte coincidentes. Inician la singladura juntos, no sin zigzagueos difícilmente explicables en el itinerario presentado por la crónica, hacia el canal de la Mancha. Los aliados deciden, pese a los malos semblantes del tiempo, dar el salto desde el continente a Inglaterra. La amenaza se convierte en real y Gutierre Díaz describe con su personal pericia otra peligrosa tormenta. Tal es la dispersión que causa ésta entre las galeras francesas y castellanas que tardan hasta quince días en reunirse. Desde las islas de Abrevack, donde logran encontrarse tras la tormenta, navegan hasta Cornualles, su objetivo. El desembarco en Saint-Ives, o tal vez Saint-Erth ("Chanta", en el texto) supone la quema del puerto y la captura de dos naos, que Pero Niño envía como botín a Harfleur (c. 68). A continuación, se dirigen a Dartmouth. Allí, desacuerdan el capitán castellano y el francés sobre la conveniencia de realizar un ataque, tal como propone Pero Niño. Éste termina cediendo ante la cabal llamada a la prudencia de mosén Charles.

De Dartmouth reman las cinco galeras hasta Plymouth. Los navíos ingleses se esconden y desde el puerto lanzan tantas lombardas que obligan a retroceder a los aliados para evitar ser hundidos. A la entrada del golfo de Exeter están a punto de perecer, a causa de la fuerza de la peligrosa corriente del golfo. Pero lo consiguen superar hasta su clausura, en Portland, que saquean aprovechando la indefensión de sus pocos y mal armados lugareños. El saqueo y quema de Portland, por lo que nos cuentan El Victorialy los cronistas franceses fue protagonizado principalmente por los franceses. Gutierre Díaz quiere exculpar a los de Pero Nińo, aclarando que no quisieron participar en la quema "porque la gente de la isla era pobre".

18 Para el personaje de Avendaño, en su contexto diacrónico familiar, véase Ernesto García Fernández, "El linaje Avendaño: causas y consecuencias de su ascenso social en la Baja Edad Media", Anuario de Estudios Medievales, 37/2 (2007), pp. 527-61. 
Aunque finalmente tuvieron que acudir en apoyo del grupo francés, en franco aprieto (c. 72). Lo contrario sucede en el siguiente puerto, Poole, patria, como hemos dicho, de uno de los más dañinos corsarios ingleses, Harry Paye, donde los castellanos desembarcan solos y los franceses lo hacen mucho más tarde, cuando los ven en apuros. El capítulo de Poole detalla a la perfección los destrozos, quema y toma de posiciones de los hombres de Pero Niño. A través del pormenor, Gutierre Díaz quiere transmitir por todos los medios recuerdos vivos y sensaciones pavorosas e imborrables de peligro: “...e pusiéronse tan acerca que bien vería el hombre el que era vermejo o negro dellos. E traían puertas de casas e asentávanlas en tierra, e un madero detrás [...]; e salían detrás dellas e peleavan”. El fragor de la batalla impide incluso la carga normal de las ballestas: "e las frechas eran tantas, e venían tan espesas, que los ballesteros non se osavan abaxar a armar las ballestas, ca avía ya muchos feridos de las frechas. E tantas eran, que los que tenían jaques o sobrevistas [...] parescían asaeteados. La bandera, e el que la tenía, era tan lleno de frechas, e tenía tantas alderredor de sí, como un toro quando anda en el coso corrido" (c. 73).

Pero Niño accede al deseo de los cómitres de dar por cancelada la campaña de ese año e ir a invernar a algún puerto francés, pero con una condición: que sea satisfecha su curiosidad de ver Londres. Y tal vez los marinos estimaran ese capricho demasiado peligroso, porque lo cierto es que Gutierre Díaz nos presenta Londres a dos leguas del mar, situado "en un llano", frente a la isla de "Duy" (Wight). Posiblemente ni Pero Niño ni Gutierre Díaz descubrieran nunca el fraude, pero naturalmente el lugar al que se refiere Gutierre Díaz no era Londres, sino con toda probabilidad Southampton (c. 75).

Las galeras dejan las costas inglesas con rumbo a Bretaña, reponiendo provisión de carne en alguna de las pequeñas islas anglonormandas (Jersey o Aurigny). Y "non fizieron otro mal, por quanto es gente pobre" (c. 76). Llegados a Harfleur, que Gutierre Díaz describe, quedan alojados. Tras un frustrado intento de regresar a Inglaterra, deciden Savoisy y Pero Niño ir a invernar a Ruán. La estancia allí es difícil de resumir en pocas líneas. Cerca de Ruán, en Sérifontaine ("Xirafontayna”) habitaba Renaud de Trie, un anciano enfermo, que había sido consejero de Carlos VI, almirante de Francia y poseedor de otros relevantes cargos. Conociendo la empresa de Pero Niño, le invita a pasar tres días en su mansión. Y esos tres días hubieron de dejar un recuerdo imborrable en la memoria de Pero Niño y Gutierre Díaz, que se plasma en un capítulo de El Victorial (c. 78) como la imagen preciosista e idealizada en la miniatura de un libro de horas, pero también como un verdadero cuadro de costumbres, fiel daguerrotipo de una escena rebosante de vida en pleno gótico francés. El viejo guerrero esperaba la muerte en su paraíso privado, rodeado de montes y bosques, jardines y estanques, servidores y músicos, canes ("quarenta o cinquenta") y caballos ("fasta veinte cabalgaduras") de diversas razas. Y acompañado de su mujer, la joven, hermosa y noble Jeanne de Bellen- 
gues. Se puede sospechar que entre Pero Niño y la casada francesa existió un inicio de relación amorosa, puesto que se dice claramente que Pero Niño se alojó "en casa de madama", después de anotar que "ella tenía su gentil morada aparte de la del almirante" e insistir en que su marido estaba enfermo ("era doliente"). Dado ese precario estado de salud, Jeannette de Bellengues pudo aspirar a asegurarse el futuro incierto. De hecho, la historia de las relaciones entre ambos no hizo sino comenzar aquí; porque tras su estancia en París: "finó el buen cavallero almirante de Francia, e madama de Xirafontaina embió por Pero Niño, e fabló con él toda su fazienda. E de allí adelante fueron enamorados" (c. 83). Madame le enviará a Pero Niño presentes valiosos, mientras que éste hablará con el padre de ella, comprometiéndose ambos a esperar dos ańos (cs. 85-86). Y, sin embargo, finalmente, Pero Niño preferirá antes seguir en Castilla, luchando en la frontera de Granada, que regresar a cumplir su compromiso, que a la larga habrá de cancelarse (c. 89).

Tras esos tres intensos días, Pero Niño va a París a reclamar ante el Consejo de regencia la paga de sus galeras, pues "avía gastado ya el sueldo que avía llevado de Castilla". Al parecer, su enfado y graves acusaciones en el Consejo fueron un último recurso, tras habérsele ido dando injustamente largas. Recibe a partir de este lance amables invitaciones de los duques de Orleans y Borgoña, y el de Orleans lo integra entre los hombres de su casa (c. 79). Pero Niño combate en una prueba ("ensay") en la plaza de "la petita Bretaña", cerca de lo que hoy es el Louvre, donde quiebra varas. Al poco, en otra plaza, "la Costura de Santa Catalina", tiene lugar otra justa entre más de cien caballeros. Pero Niño se mantiene en ella invicto, luchando contra muchos anónimos oponentes y, luego, contra una terna de caballeros a cual más peligroso. Así que, por lances deportivos y amorosos, la persona de Pero Nińo comienza a ser conocida en ambientes cortesanos parisinos. Prueba de ello es la carta que se le envía -y que GDG traduce (c. 84)-, en la que se le propone formar parte, en sustitución del famoso Guillaume du Châtel, del grupo de siete combatientes que recogían el desafío a muerte lanzado por el caballero catalán Ponce En-Perellós, defensor con otros seis de "la Dama Blanca". Pero Niño contesta con otra carta (c. 85), aceptando la invitación a participar en la liza, que finalmente no se realizará por intervención del rey. ${ }^{19}$

$\mathrm{Al}$ acercarse el verano, se abre nuevamente la campaña marítima. Zarpan de Ruán, camino de Harfleur, cuando les sorprende un eclipse de sol (que efectiva-

19 Véase, para estos episodios, R. Beltrán, "Convergencias caballerescas entre El Victorial y Curial e Güelfa: del accessus biográfico al contexto histórico de la París de 1405”, eHumanista, 16 (2010), pp. 442-59; y, más concretamente, para la fama de Guillaume du Châtel en la literatura del siglo XV, R. Beltrán, "El mariscal Boucicaut, Guillaume du Chastel i Pere de Cervelló al Curial e Güelfa i al Jehan de Saintré: connexions històriques i literàries", en Antoni Ferrando (ed.): Estudis lingüistics i culturals sobre "Curial e Güelfa", novel-la anònima del segle XV en llengua catalana I Linguistic and Cultural Studies on 'Curial e Güelfa', a 15th Century Anonymous Chivalric Romance in Catalan. Amsterdam: John Benjamins, 2012, pp. 157-200. 
mente tuvo lugar el 16 o 17 de junio). En Harfleur se reúnen con la flotilla de Savoisy y con tres balleneres más. En Crotoy anclan y reponen vituallas. Informados de que en la costa de Cornualles, castigada por ellos el ańo anterior, se hallaban sobre aviso, deciden atacar las costas del mar del Norte. Así, cruzan el paso de Calais y llegan a Orwell. El propósito era tomar tierra allí, pero el viento forzó las naves hacia el sur, hasta "El Esclusa" (Sluys). Visitan la vecina Brujas, donde Pero Nińo se entretiene, como es lógico, haciendo algunas compras, aunque sin anotar Gutierre Díaz nada personal sobre este emporio. Por aquellos días, cuatro naos portuguesas se salvan de ser tomadas por Savoisy gracias a la intercesión de Pero Niño, puesto que Portugal estaba en tregua con Castilla (c. 86).

De nuevo en ruta, a la altura de Calais, que es descrita, encuentran una flota inglesa. El combate que se entabla contra ésta es detallado y acaba con la retirada de franceses y castellanos por culpa del viento contrario (c. 87). Regresan los aliados a puerto francés, Gravelines y Crotoy. El viento impedía todo intento de salida, así que Charles de Savoisy, "gastado" y "non pudiendo contentar la gente", se hubo de despedir de Pero Niño. Singlando a la altura del cabo Caux, encuentra Pero Niño seis balleneres franceses -que sabemos que hacían de guardacostas de Normandía- con quienes hace liga, ya que iban también "a la ventura buscando navíos de ingleses". Los normandos le proponen un ataque a Jersey, la isla del canal (c. 76), contando con el auxilio de unas naves francesas que iban a cargar sal a Bretaña. Históricamente, al parecer, Héctor de Pontbriand, un bretón que menciona Gutierre Díaz, llevó la mayor responsabilidad del ataque, pero El Victorial le concede solamente el papel de subordinado. ${ }^{20}$ Desembarcan en Jersey y unos mil hombres de armas son perfectamente ordenados en disposición de batalla por Pero Niño, frente a tres mil ingleses (más doscientos a caballo). El enfrentamiento y victoria de los aliados es detallado: la primera acometida desordenada de los ingleses; el encontronazo posterior de las escuadras principales, primero con lanzas, luego, con hachas y espadas... Pero Niño exige hablar con los principales para negociar la entrega a él de la isla: "vos sojuzgar a mí en nombre de mi señor el rey de Castilla". Pero los isleños le argumentan tan sólidamente las razones de su acatamiento al rey inglés, que Pero Niño pacta el pago de "diez mil coronas para repartir a la gente darmas", más un impuesto a pagar en armas durante diez ańos (lo que parece más difícil de creer, dadas las dificultades de cobro). Y Gutierre Díaz corrobora el acierto de la decisión con un ejemplo referido a Alfonso XI y la batalla del Salado.

En Brest se hace el reparto del botín y el dinero. Pero Niño, solicitado en Castilla, se despide con un mensajero del rey y los duques franceses y emprende regreso, cruzando con dificultades el peligroso ras de Saint-Malo y el ras de Blanchart. Tomando el camino de La Rochela, se encaminarán hacia las costas castellanas.

20 Véase, para el episodio, E.T. Nicolle, "Le Victorial and the Attack on Jersey in 1406", Bulletin Annuel de la Société Jersiaise, 1923, pp. 32-46. 
De Santander, pasando por su casa de Valladolid, Pero Niño se dirige a la corte en Madrid donde el rey lo recibe, arma caballero y promete "poner en muy mayor estado". Lamentablemente, al poco muere el rey, frustrándose la esperanza puesta en sus promesas.

Tras la lectura de estas dos campañas de El Victorial, en tantas ocasiones arrimadas como un diario, día a día, e incluso minuto a minuto, al devenir de los hechos, asalta la lógica pregunta en torno a cómo pudo mantener Gutierre Díaz esa exactitud, escribiendo su obra al menos veinticinco años más tarde de los acontecimientos narrados. Acrecienta esa perplejidad el extremo detallismo con que se plasman algunos momentos de la campaña, como éste del regreso hacia España desde Berbería, cuando parece que nos encontremos en el alcázar de proa de la nave, viviendo la operación:

Partieron las galeas de Alhabiba e fallaron tormenta en la mar e el viento del poniente rezio. Los mareantes temprano endereçaron todas sus cosas: concertaron las brúxulas, cevadas con la piedra imán; abrieron las cartas de navegar e començaron a puntar e a compasar, que la rota era larga e el tiempo contrario; miraron el relox: diéronlo a hombre bien atentado; guindaron los artimones, calaron timones de caxa, e dieron remos de luengo. Començaron de navegar en nombre de Dios. Singlaron todo el día, el viento e las mareas al quartel de proa. Embestían las olas fasta media galera. (...) A puesta de sol, paresció la luna, e comió poco a poco todas las nubes e la escurana, e paresció la luna clara. Tornó el viento al sur. Ansí navegaron toda la noche, con mucho afán (c. 50).

Es a partir de la confrontación del relato de estas campañas con otros "diarios" marítimos de la Crónica de Juan II de Álvar García de Santa María, muy similares en el uso del lenguaje de la marinería y en la estructura narrativa, y muy pocos años posteriores (1407 y 1410) a los hechos recogidos por Gutierre Díaz, cuando se puede inferir que alguien, al lado del futuro conde, como solía ser preceptivo, llevó puntualmente un "diario de a bordo", destinado como relación de campaña al expediente y archivo de la cancillería real. Este mismo "diario" es el que, reelaborado con unas intenciones muy diferentes a las del primero, y tal vez por la misma persona que escribiera aquél (pues muy bien pudo el propio alférez Gutierre Díaz ser escribano de la galera de Pero Niño), podemos leer hoy en la segunda y magnífica parte de El Victorial. ${ }^{21}$

21 Véase R. Beltrán, "Del 'diario de a bordo' a la biografía: las campañas marítimas (1407 y 1410) en la Crónica de Juan II de Álvar García de Santa María y la doble redacción de El Victorial", Anuario de Estudios Medievales, 20 (1990), pp. 171-209. 


\section{Desde la campaña de Granada (I 407) hasta el exilio (I 422)}

Se reanudaba por entonces la guerra de Granada, que va a concentrar las prioridades militares del regente don Fernando, justamente llamado "de Antequera" por su victoria (que culminaría la campaña fronteriza) en esa plaza, en 1410 . Cuando el rey propone enviar como embajador a Francia a Pero Niño, él prefiere acudir a Granada y aporta a la campaña, además de su esfuerzo personal, la colaboración de "sesenta hombres darmas, todos bien encavalgados, e armados cada uno de dos bestias, e todos jaques de su librea”. La llamada campaña de Setenil, en 1407 , centra la primera fase de la ofensiva castellana que culminaría con la conquista de Antequera. Pero Niño destaca, antes, en Ronda, escaramuzando ante la plaza y entrando en liza con sus defensores, en un capítulo que recoge, mencionando de modo destacadísimo al propio Pero Niño, la Crónica de Juan II (c. 89). Pero también luchará en la misma Setenil, desde la manta en el ataque, o dirigiendo la recuperación y traslado de las "lombardas" perdidas. ${ }^{22}$

Pero Nińo obtiene, tal vez gracias en parte a su destacada actuación militar en Granada, una de las capitanías de la guardia del rey. Por ello, quedará ligado a la corte, y a la larga obligado a tomar partido por alguna de las facciones dominantes. En 1409, el episodio de los amores de Pero Niño con Beatriz de Portugal iba a tener no sólo importancia en su biografía, pues se trata de su segunda esposa, sino una fuerte resonancia en la corte, a juzgar por los ecos que llegan no sólo a $E l$ Victorial (cs. 90-94), sino a la Crónica de don Álvaro de Luna (c. 90). ${ }^{23}$ El infante don Juan de Portugal, hijo del rey don Pedro y de la infortunada Inés de Castro, había tenido que refugiarse en Castilla, en 1380, tras haber matado a su mujer, María Téllez, acusada injustamente de traición. Juan I de Castilla, nos recuerda $E l$ Victorial, acogió benignamente a su tocayo el infante portugués y lo casó con uno de los mejores partidos de Castilla, su hermana bastarda doña Constanza, hija de Enrique II y de una dama aragonesa. El infante recibió las ciudades de Alba de Tormes y Valencia, que por él tomó el sobrenombre de Valencia de don Juan. Pues bien, la menor de las tres hijas del matrimonio iba a ser la segunda mujer de Pero Nińo. El encuentro entre los futuros esposos tiene lugar en Valladolid, en medio de unas fiestas. La actuación de Pero Niño es defendida por Beatriz. Su favorable juicio llega a oídos de Pero Nińo, que "en aquella ora fue firmado

22 Estudié el episodio de Setenil con algún detalle, con propuestas de aclaración para sus varias y graves incoherencias narrativas, que sólo la lectura confrontada de la Crónica de Juan II ayuda a recomponer, en R. Beltrán, "Convergencias y divergencias en la narrativa cronística de la guerra de Granada: la campaña de Setenil (1407)”, Boletín de la Biblioteca Menéndez Pelayo, LXVI (1990), pp. 5-45.

23 El personaje de Beatriz de Portugal -y sus homónimas- ha de ser reevaluado a la luz del trabajo de César Olivera Serrano, Beatriz de Portugal. La pugna dinástica Avis-Trastámara. [Cuadernos de Estudios Gallegos, Anexo XXXV]. Santiago de Compostela: Instituto de Estudios Gallegos 'Padre Sarmiento' (CSIC-Xunta de Galicia), 2005. 
en su coraçón de amar aquella donzella, a fin de su honra" (c. 91). Pero Niño "se atreve" a la aventura de conquista de Beatriz. "Amar" se hará a partir de aquí, con total normalidad, sinónimo de buscar el matrimonio. ${ }^{24}$ Pero Niño enviará su embajada, pidiéndole que "la pluguiese que él se llamase su caballero", e insistirá tratando de ganar voluntades en quienes la rodean, en especial la del hermanastro de ella, don Fernando. No se trataba de cautivar sino de convencer y Beatriz es convencida hasta el punto de que conciertan casamiento y se desposan en secreto (c. 92). El problema viene cuando las noticias del matrimonio secreto llegan al infante don Fernando, que "tenía fablado e acordado su casamiento en otras partes donde a él cumplía mucho" (c. 93). El Infante interroga a Pero Niño y a Beatriz, por separado, y ambos - pero en especial ella ("ella pusiera en su voluntad de allí adelante de non casar sino con quien ella quisiese”)-, hacen gala de una sorprendente independencia de criterio. El interrogatorio tendría lugar en Magaz, seguramente en enero de 1410 . Pero Niño se ve obligado a huir a Bayona. La reina madre evita su detención y la de la propia Beatriz, que, sin embargo, llega a ser retenida ("guardada") en Urueña. En el ańo y medio de encierro que sufrió la visitó Pero Niño secretamente tres o cuatro veces. Y finalmente se logró el perdón del Infante y el reconocimiento del matrimonio.

Don Fernando de Antequera, reconciliado totalmente con Pero Niño, le hace entrega de los burgos de Valverde y Talaván, y le promete mayores mercedes para el futuro. Desgraciadamente muere antes de un ańo, en abril de 1416. En 1415 tuvo lugar el viaje de doña María de Castilla a Valencia, para contraer matrimonio con el hijo de don Fernando (recién elegido rey de Aragón, en el compromiso de Caspe, de 1412), el futuro Alfonso el Magnánimo. Una gran comitiva de militares y diplomáticos castellanos acudió al reino vecino, para asistir a la boda. De ella formaba parte Pero Niño, como nos indica El Victorial (en el c. 96, con cierto desajuste cronológico), cuya participación destacada en los torneos testimonia también la Crónica de Juan II. Y una de las primeras acciones de Pero Niño como oficial de la guardia sería la que se cuenta en el c. 95, pudiendo ser datada hacia 1418 o 1419. El obispo de Plasencia, Vicente Arias de Balboa, había muerto en 1414 y Benedicto XIII proveyó la vacante a favor de Gonzalo de Stúñiga. Pero el rey defendía que la mitra se otorgase a don Gutierre Álvarez de Toledo, uno de los religiosos de mayor personalidad de todo el siglo XV, que sería obispo de Palencia y Toledo, arzobispo de Sevilla y primer señor de Alba de Tormes (el futuro ducado de Alba). ${ }^{25}$ Gonzalo de Stúñiga se hizo fuerte en la ciudad, apoyado por muchos

24 Madeleine Pardo, "Un épisode du Victorial: biographie et élaboration romanesque", Romania, LXXXV (1964), pp. 269-92, estudia cómo el episodio representa perfectamente el equilibrio entre biografía y relato novelesco, entre realidad y literatura, que preside todo El Victorial.

25 Véase, para la biografía del arzobispo -incluido el episodio que menciona El Victorial-, José Manuel Nieto Soria, Un crimen en la corte: caida y ascenso de Gutierre Álvarez de Toledo, Señor de Alba (1376-1446). Madrid: Sílex, 2006. 
miembros de su importante familia. Y a Pero Niño le fueron dadas órdenes para que, en nombre del rey, se personase en Plasencia e hiciera ocupar la sede episcopal a don Gutierre. No lo consiguió, ni él ni otros, pese a lo que deja insinuado el texto, porque Gonzalo de Stúñiga se mantuvo en Plasencia hasta 1422. Pero el episodio le sirve a Gutierre Díaz para adelantar que la intervención le granjearía a Pero Niño -como se vería en los episodios de 1420- el odio del bloque familiar de los Stúniga, más el del todopoderoso Juan Hurtado de Mendoza.

A la muerte del rey, Sancho de Rojas, Juan Fernández de Velasco y Diego López de Stúñiga se erigen como continuadores de la política seguida bajo Enrique III, exigiendo para el resto de la minoridad de Juan II el cumplimiento estricto de su testamento. Comienza entonces en firme la labor de los belicosos infantes. (Gutierre Díaz expone la situación de los años 1416-1419, aunque hay notables incoherencias en el texto.) Los partidarios de la facción del infante Enrique, maestre de Santiago, entre quienes, como deudo de su padre Fernando de Antequera, estaba Pero Niño, se unen para contrarrestar el poder de Sancho de Rojas. Y un enemigo claro despunta: Juan Hurtado de Mendoza, quien "non dava lugar a ningunos cavalleros en la casa del rey, sino que todo pasase por su mano". Se están colocando los cimientos para la acción de Tordesillas. En efecto, entre el verano de 1419 y el siguiente se iría forjando en la mente del infante don Enrique el proyecto de adueñarse del poder mediante un golpe de fuerza. El 12 de julio de 1420 se reunieron los conjurados y el 13 detuvieron al rey.

Pero Niño, capitán de la tercera parte de la guardia real y por tanto pieza estratégica importante, es invitado a formar parte de la conjura, en medio de un curioso conciliábulo de tintes románticos. Pero Niño "tomó la empresa", una empresa que le iba a costar el exilio, insistiendo Gutierre Díaz en su creencia de que "era ansí en servicio del rey". Gutierre Díaz refleja el momento en el que intervino Pero Niño en el apresamiento de Juan Hurtado, atenuando los aspectos más violentos: "detóvolo muy atentamente e [lo] más cortés que él pudo, non ovo sangre...". Gutierre Díaz quiere mostrar a Pero Niño limitándose al estricto cumplimiento de su deber oficial. Pero Niño tuvo, sin embargo, mucha mayor implicación que la que parece deducirse de este pasaje, como nos confirman las versiones alternativas de la Crónica de Juan II y la Crónica de don Álvaro. Claramente, Gutierre Díaz quiso exculpar a Pero Niño de su implicación directa en el atraco mediante una versión que suavizara los hechos, reivindicando que Pero Niño creía sinceramente que aquella era la mejor manera de hacer "servicio" (es la palabra clave del episodio) al rey.

En manos todavía el rey de los enriqueños, se le da la tenencia del estratégico alcázar de Segovia a Pero Niño. Gutierre Díaz resume los traslados del grupo en el poder a Ávila, primero, a Talavera después. Presenta a don Álvaro de Luna, y con éste la huida del rey hasta el castillo de Montalbán, donde se hizo fuerte. El castillo es asediado, pero Gutierre Díaz vuelve a insistir en la reivindicación de la firme leal- 
tad de Pero Niño, a través de un supuesto diálogo que se daría entre éste, el conde de Benavente y el rey. Los de don Enrique han de levantar el campo, y Pero Niño marcha a Ocaña, con el infante. Gutierre Díaz reseña la devolución que Pero Niño hizo del alcázar de Segovia al rey. La posición de don Enrique cae en picado hasta que es detenido, en junio de 1422. Pero Niño se encierra en el castillo de Montánchez durante más de un año, hasta que se ve obligado a abandonarlo y partir hacia el exilio, en principio en Valencia, "a pie" y "ballesta al cuello" (c. 95).

\section{Desde el regreso a Castilla (i 425 ) hasta la muerte (I 453 )}

Gutierre Díaz suple la falta de noticias de Pero Nińo durante su destierro en el reino de Aragón con una síntesis de acontecimientos políticos hasta finales de 1425, cuando el Tratado de la Torre de Araciel supone la recuperación de bienes de don Enrique y el perdón para los exiliados. Antes incluso, a decir de Gutierre Díaz, regresa Pero Niño a sus lugares en Burgos, donde espera paciente la reconciliación, que vendrá por intercesión de don Álvaro de Luna, al parecer necesitado de fidelidades incondicionales como -y se iba a demostrar en adelante- sería la de Pero Niño. Entre mayo y junio de 1428 se celebraron en Valladolid unas fastuosas fiestas, en las que los infantes, don Álvaro y el propio rey rivalizaron en gastos para poder sufragar los desfiles y torneos que se sucedieron. Francisco Rico ha apuntado la posible relación entre estas fiestas y la famosa evocación en las celebradas coplas XVI y XVII de Jorge Manrique a la muerte de su padre. ${ }^{26}$ Uno de los días, en mezcla sacroprofana, el rey se vistió de Dios Padre, acompañado de doce caballeros vestidos de apóstoles: "Pero Niño fue uno de los doze cavalleros que eran fechos en memoria de los doze apóstoles, e avía nombre Sant Pablo; e él quebró varas, e fizo más encuentros que otro ninguno”.

Pero las fiestas "engendraron muchas malquerencias e aborrescimientos", y tras la nueva alianza entre los infantes en 1429, amenazando con la invasión de Castilla, encontramos a Pero Niño en un par de lances, siempre al lado del condestable Luna. Y en Atienza, en medio de un extraño rebato, éste llamará a Pero Nińo "conde de Alba", como premonizando lo que dos años más tarde se iba a confirmar: la concesión de un condado, si no de Alba, sí de Buelna.

Sigue la participación de Pero Niño cerca de los episodios de quema de Cetina y toma de Ariza, en agosto de 1429; y la toma nuevamente de Montánchez, de donde había huido el mismo Pero Niño pocos ańos antes y cuya tenencia reivindicaba, aunque nada diga al respecto El Victorial. En 1431, Pero Nińo toma parte en la cantada batalla de La Higueruela (c. 97), a cargo de las guardas del rey, del real, del campo y de los forrajeros o "herveros". Su mayor botín consistió, al parecer, en tomar para sí y los suyos las tiendas del real moro. Pero se dio un hecho 
esencial antes de la batalla. La víspera, a Pero Niño le fue otorgado el condado de Buelna por el rey. El Victorial da la noticia así de lacónicamente: "Pero Niño en aquella sazón era ya conde, que lo avía fecho el rey el día de ante que cuidaron aver la batalla".

Podía haber sido el de Alba, o también otro sobre el señorío de Cigales, Berzosa y Fuentebureba, que le habían correspondido por herencia -y más teniendo en cuenta que en Cigales tenía su casa-; sin embargo, fue Buelna, en las Asturias de Santillana, donde Pero Niño tenía también vasallos y herencia recibidos del señorío de la Vega, por parte de su madre. ${ }^{27}$ En contrapunto a esa incomprensiblemente escueta mención en El Victorial, la Crónica de Juan II dedica todo un capítulo a la concesión del condado a Pero Niño: "En este año en el real sobre Granada, fizo el Rey Conde a Pero Niño, señor de Cigales e de Valverde, el cual fuera buen caballero, e fuera criado e doncel del Rey don Enrique, padre del Rey, e en este tiempo aprobara muy bien en fechos de caballería, así por tierra en las guerras que el Rey don Enrrique hobiera, como por la mar, donde andoviera con ciertas galeras por su mandado..." ${ }^{28}$ A continuación, la misma crónica no deja duda sobre la mediación decisiva de don Álvaro. La concesión del monarca se hizo: "a petición del condestable, que se lo suplicó mucho [...] porque este Pero Niño era de su casa, e había dél acostamiento..."

El hilo de la biografía del conde no se vuelve a tomar en su biografía, en $E l$ Victorial, hasta nada menos que doce años después, en 1444. Se inicia un paréntesis de silencio histórico, que tratan de compensar las menciones a las vidas de sus hijos, y en especial a la del primogénito Juan Niño. De ese paréntesis cronístico, sabemos cómo el período 1431-1437 coincidió con un relativamente tranquilo gobierno de don Álvaro. Y conocemos algunos de los hechos que ocuparían a Pero Niño: el problema de los vasallos solariegos en Buelna (1431), las segundas justas de Valladolid (1434), el primer testamento (1435), la firma de convenios (1436) y privilegios. Acciones legales, judiciales, representativas..., que afectaban a su casa, a su patrimonio y a su cargo. En el período de retorno de los infantes de Aragón (1437-1445), sin embargo, el contexto cambia notablemente y vemos al conde de nuevo inmerso en asuntos de política más general: no sólo en la recepción al infante don Enrique (1439), sino en su participación en el Seguro de Tordesillas (1439) o en el apoderamiento de Valladolid (1440), etc., acciones que, de otro lado, nada extraordinario decían en favor de su apoyo incondicional al rey, idea alrededor de la cual se quiere redondear esta última parte de El Victorial.

27 Se ha intentado sin éxito encontrar el documento de concesión del condado. Pero es explicable su pérdida, habida cuenta de los pleitos suscitados a la muerte del conde, que duraron varios siglos.

28 El mismo capítulo reseña también la concesión del condado de Ribadeo a Rodrigo de Villandrando, en Zamora. La Crónica de don Álvaro de Luna presenta a Pero Niño en el cortejo de la batalla de La Higueruela, titulándolo ya "conde". 
Las páginas dedicadas a los hijos de Pero Nińo pudieron ser concebidas como colofón biográfico de El Victorial, tal vez después o junto a la presentación -pero esto es mera hipótesis- de algún pliego solemne con la proclamación de Pero Niño como conde. Seis hijos, dos varones y cuatro mujeres, tuvo el conde de BueIna con doña Beatriz. Juan Niño, el primogénito, recibe, como es lógico, un tratamiento especial. Don Juan Niño, o don Juan de Portugal, nació poco después del matrimonio de Pero Niño con dońa Beatriz, entre 1412 y 1415 , pues sabemos que murió, con "veinte e quatro años, aún no cumplidos", entre 1435 (fecha del primer testamento de Pero Nińo, en que aparece como heredero indiscutible) y 1438, cuando el rey concede que sus bienes le fueran delegados al segundo hijo, don Enrique. Juan Niño participó en algunas acciones militares (Cetina, Vega de Granada...) junto a su padre, y en al menos dos acontecimientos caballerescos relevantes: en las justas de Valladolid, en mayo de 1434, y muy destacadamente en el célebre Paso Honroso sobre el puente de Órvigo, en agosto del mismo año. Nada informa sobre estas acciones El Victorial, que en cambio se entretiene en contar al detalle un conflicto vecinal con el señor de Mucientes y adelantado de Galicia. Tal vez una pérdida de folio o folios del texto original nos impide conocer las causas de su muerte prematura.

Don Enrique quedó, a la muerte de don Juan de Portugal, como único varón legítimo y heredero. Casó con doña María de Guzmán, hija de Pedro Núnez de Herrera y Blanca Enríquez. Pero moriría también tempranamente, entre 1439 y 1441, lo que debió ser especialmente lastimoso para el conde Pero Niño, que dirigirá a continuación sus afanes a la obtención de óptimos casamientos para sus hijas. Doña Constanza fue seguramente la mayor. Su muerte acaeció antes de 1435, pues no es nombrada junto a las otras hijas en el primer testamento del conde, de esa fecha. Doña Inés siguió la suerte de tantos segundones de familias nobles. En el testamento de Pero Niño de 1435 se habla de "doña Inés la monja" (en Rapariegos), pero sabemos por el segundo que en 1441 había ascendido a abadesa del convento de Santa Clara de Valladolid. No hizo prevalecer los derechos que tenía sobre la sucesión de Pero Niño, cediéndolos a sus hermanas y cuñados a cambio de una cantidad que probablemente dedicaría a la reforma del convento. Doña María casó con el mariscal García González de Herrera, señor de Pedraza y otros lugares. Había heredado Cigales, la principal posesión de Pero Niño, y partió con su hermana doña Leonor los bienes de su padre en 1458. La única hija de su matrimonio con González de Herrera, Blanca Herrera, casaría con Bernardino Fernández de Velasco, condestable de Castilla, hijo y sucesor del también condestable Pedro Fernández de Velasco. ${ }^{29}$ Doña Leonor, por su par-

29 Véase, respecto al mariscal Herrera y su relación con la familia y propiedades del conde de Buelna, el detallado y completo estudio, ya citado, de Franco Silva, El mariscal García de Herrera y el marino don Pedro Niño. 
te, casó con Diego López de Stúñiga, hijo del mariscal don Íñigo de Stúñiga y de doña Juana de Navarra (bastarda del rey Carlos III), y hermano de Lope de Stúníiga, el poeta del Cancionero de Stúniga, contra quien se había enfrentado Pero Niño en el Paso Honroso. A estos hijos, en fin, hay que añadir el nombre de don Pedro, habido de su primer matrimonio con doña Constanza (mencionado en el c. 33 de El Victorial). Y el de al menos un hijo ilegítimo. ${ }^{30}$

El Victorial, en fin, solamente vuelve a presentar al conde Pero Niño en acción a propósito de la toma de Peñafiel. Tal vez porque sólo allí éste, pese a su avanzada edad, volvería a alzar su cansada espada, para mostrar su inquebrantablemente fidelidad al rey. Antes, en 1443 Juan II quedó prisionero de la facción liderada por el infante don Juan en el llamado golpe de estado de Rámaga. La situación duró más de medio año y el rey de Navarra se refugió, con el rey prisionero, en Tordesillas. Aunque no tenemos constancia cronística de la participación de Pero Niño en la liberación del rey, El Victorial lo presenta rendido a su servicio: "se ofreció por su persona, con toda su casa, e con todos los suyos, dispuesto a morir...". El rey logró escapar el 15 de junio. En su camino de encuentro con su hijo, pasó por Cabezón y Dueñas, y a ambos lugares fue a hacerle reverencia Pero Niño, desde su villa de Cigales. Después, le auxilió en la toma de Peñafiel, entre julio y agosto de 1444. Ésta será la despedida bélica del conde, a quien ya no hallaremos en Olmedo, el año siguiente.

La muerte de la condesa Beatriz, su segunda mujer, tuvo lugar dos ańos después de Peñafiel, en concreto en noviembre de 1446. Cuando muere ésta, "quedó el su conde e buen amigo muy triste e muy cuitado por la su muerte, e ansí lo será toda su vida, ya de edad pasados setenta años". Nada nos informa El Victorial sobre el tercer matrimonio de Pero Niño. Y es que el epílogo de la crónica biográfica es muy confuso. Un simple párrafo epidíctico concluye que Pero Niño ha luchado por mar y tierra, entre los quince y los setenta ańos, siempre triunfante; por lo que, pese a que puede seguir luchando y venciendo, ha de darse por contento. Poseemos el testamento de la condesa. ${ }^{31}$ Dońa Beatriz cedía a Pero Niño la posesión de todos sus bienes, y le hacía testamentario y apoderado absoluto: "por quanto á tiempo que yo me casé e desposé con el señor conde don Pero Niño, é é[l] perdió mucha de su facienda para desposar conmigo contra la voluntad de algunos grandes señores deste reyno, lo qual es público é notorio, é aun estuvo fuera de los reynos de Castilla sobre ello, á do ovo grand travajo é fizo mucha

30 El 10 de diciembre de 1452, la Real Hacienda expedía un documento, exhumado por González Palencia, Don Pedro Niño, pp. 26-28, que habla de "Don Pedro Niño, vuestro hijo natural por mi legitimado". El documento demuestra el interés del conde, al filo de la muerte, por delegar en este hijo los bienes del fallecido don Enrique. En el último testamento recibió 30.000 maravedíes como herencia paterna, amén de otros legados de menor importancia.

31 Lo transcribe José Vargas Ponce, Varones ilustres de la marina española: Vida de don Pero Niño, primer conde de Buelna. Madrid: Imprenta Real, 1807, apénd. nº XI, pp. 263-69. 
costa sobre ello, é otrosí me ofreció algunos de sus bienes á parientes mios, de lo qual tengo grand cargo dél”.

Pero Niño casó en terceras nupcias, en fecha sin determinar, con doña Juana de Stúniga, sin tener sucesión. ${ }^{32} \mathrm{El}$ conde de Buelna murió el 17 de enero de $1453 .{ }^{33} \mathrm{Al}$ morir sin dejar descendencia masculina, pretendió el condado su sobrino, Alfonso Niño, merino mayor de Valladolid. Se lo confirmó el rey Juan II el mismo 17 de enero de 1453. Pero el 8 de febrero del mismo año el infante don Enrique libraba una cédula a favor de García González de Herrera y doña María Niño para que se les entregara el condado. Esta discrepancia originaría un pleito, que duraría hasta el siglo XVII. ${ }^{34}$ Poco después de la muerte de Pero Niño se había deshecho el condado, que fue vendido en 1461 por González de Herrera y doña María (con la aprobación de doña Leonor, la segunda hermana) a Juan García Manrique, II conde de Castañeda. Una parte de la ganancia por la venta iría a las monjas de Santa Clara de Valladolid, en donde era abadesa doña Inés, la tercera hermana. ${ }^{35}$

La vida de Pero Niño, tal como nos es contada por Gutierre Díaz de Games, es como la vida de tantos caballeros de la ficción y de la historia que un famoso hidalgo manchego confundiría, dos siglos después, como una y la misma cosa. Hallamos en El Victorial, en efecto, una construcción armónica del universo caballeresco que perfectamente podía haber estado almacenada en la cabeza de don Quijote: sin fisuras, sin contradicciones, como destinada a conjurar el desorden político y moral del mundo real. Aunque sea un relato cronístico, la organización compositiva es la de la ficción caballeresca, y el aliento ideológico fundamental

32 El documento probatorio es una promesa de arras, copiada a instancias de don Pedro, hijo natural del conde, en Valladolid, el 23 de abril de 1464, y que había sido otorgada por éste el 18 de diciembre de 1452, es decir sólo un mes antes de su muerte. Lo transcribe González Palencia, Don Pedro Niño, pp. 9-16.

33 González Palencia, Don Pedro Niño, pp. 29-31. Hasta el estudio de González Palencia se creía que el fallecimiento había ocurrido a principios de enero de 1454, puesto que Vargas Ponce transcribía un testamento de 19 de diciembre de 1453, seguido de un codicilo de 6 de enero de 1454. González Palencia demuestra la falsedad de estos dos documentos.

34 Pleito o suma de pleitos que supondría, entre otras, la pérdida de los títulos del condado de Buelna, que no han logrado salvarse. Los tenía en 1476 Alfonso Niño, el sobrino del conde, y los esgrimiría como parte de su defensa en los pleitos iniciados contra las hijas del conde (González Palencia, Don Pedro Niño, pp. 19-20 y 32-41). Al perder el pleito sus descendientes, dos siglos más tarde, se perdieron también estos testimonios valiosos. El pleito fue resuelto definitivamente en 1674, a favor de las pretensiones del condado de Aguilar, es decir reconociendo el derecho preferente de las hijas del conde. En 1928 fue rehabilitado el título de conde de Buelna a favor de don Mariano de Prado O’Neilli, descendiente de doña Leonor Niño, la hija menor de Pero Niño, el protagonista de El Victorial. Actualmente, está en posesión de su bisnieto, Miguel del Prado y Narváez, $V$ conde de Buelna.

35 Véase para el tema de la suerte del condado, mucho más ampliamente, el citado trabajo de Franco Silva, El mariscal García de Herrera y el marino don Pedro Niño. 
lo ofrece la ética aristocrática dominante en el otoño de la Edad Media. El autor de El Victorial, que no es noble, ordena la vida, entiende la vida de acuerdo con esa concepción. No hay otra posible en su tiempo. De ahí que el resultado de esta historia de la vida de Pero Niño contada por su biógrafo resulte tan contradictorio como paradójicamente armónico, tan desconcertante para el recopilador de datos objetivos como fascinante para el historiador de las mentalidades, la cultura y la literatura. De manera triste -pese a la distancia iluminadora de su humor-y profundamente desencantada, Miguel de Cervantes demostrará, justamente a través de la carrera de patéticos encontronazos de don Quijote con la realidad histórica de la España de su tiempo, que ese anquilosado orden de cosas feudal no sólo no era útil ni válido para su tiempo, sino que su mantenimiento idealizado, cruelmente pernicioso, conducía a la sinrazón. Y no sólo a un pobre hidalgo, sino -lo que era peor- a todo un imperio y a sus gentes. 